\title{
DINÂMICA DEMOGRÁFICA DA POPULAÇÃO RURAL: UM ESTUDO DE CASO NA MICRORREGIÃO E MUNICÍPIO DE FREDERICO WESTPHALEN/RS
}

\author{
Mariele Boscardin ${ }^{1}$ \\ Rosani Marisa Spanevello²
}

\begin{abstract}
RESUMO
O presente estudo tem como objetivo traçar um panorama das principais características sociodemográficas da população rural da microrregião e especialmente do município de Frederico Westphalen, norte do estado do Rio Grande do Sul, bem como discutir as implicações destas características para o meio rural local, com base nos dados do IBGE. De modo geral, a análise aponta que a região não foge ao padrão nacional e estadual no que tange às mudanças demográficas, caracterizada especialmente pela redução da população jovem e acréscimo na população idosa. Estas características não apenas confirmam mudanças na estrutura etária populacional, mas também revelam a emergência de "novas dinâmicas" do meio rural, demonstrando que muitos agricultores podem estar exercendo a atividade agropecuária associada ao recebimento da aposentadoria rural. Nestes casos, são agricultores que tendem a diminuir a capacidade produtiva e a produção agropecuária em razão de limitações de ordem física.
\end{abstract}

Palavras chaves: envelhecimento, estrutura etária, migração.

\section{DEMOGRAPHIC DYNAMICS OF THE RURAL POPULATION: A CASE STUDY IN THE MICROREGION AND MUNICIPALITY OF FREDERICO WESTPHALEN/RS}

\begin{abstract}
The objective of this study is to outline the main socio-demographic characteristics of the rural population of the micro-region and especially of the municipality of Frederico Westphalen, in the northern state of Rio Grande do Sul, as well as to discuss the implications of these characteristics for the local rural environment. in the IBGE data. In general, the analysis shows that the region does not escape the national and state standard regarding demographic changes, characterized especially by the reduction of the young population and increase in the elderly population. These characteristics not only confirm changes in the age structure of the population, but also reveal the emergence of "new dynamics" of the rural environment, demonstrating that many farmers may be engaged in agricultural activity associated with receiving rural

\footnotetext{
1 Graduada em Zootecnia (UFSM). Mestrado em Desenvolvimento Rural (UFRGS). E-mail: marieleboscardin@hotmail.com

${ }^{2}$ Graduada em Agronomia (UFSM). Mestrado em Extensão Rural (UFSM). Doutorado em Desenvolvimento Rural (UFRGS). Professora Adjunta na Universidade Federal de Santa Maria (UFSM), Campus Palmeira das Missões. E-mail: rspanevello@yahoo.com.br
} 
retirement. In these cases, they are farmers who tend to reduce productive capacity and agricultural production due to physical limitations.

Key Words: age structure, aging, migration.

\section{INTRODUÇÃO}

O meio rural brasileiro tem protagonizado nas últimas décadas uma série de transformações em decorrência de diversos fatores. Talvez a que mais ganhou notoriedade e ainda recebe "rios de tinta" refere-se à modernização da agricultura, fundamentalmente em função do seu viés tecnológico.

Notadamente, este amplo processo de mudança na base técnica da agricultura ocasionou alterações significativas na alocação dos meios de produção, especialmente capital e mão de obra, com reflexos expressivos nas dinâmicas tecnológicas e produtivas das atividades agropecuárias, nas economias locais, regionais e nacionais e no meio ambiente. Estas compreensões e reflexões estão balizadas, sobretudo, pelos debates mais clássicos de Kageyama (1987) e Silva (1996), que se propuseram em analisar a modernização da agricultura e seus efeitos.

Entretanto, este processo, também resultou em alterações e fenômenos demográficos intensos, como é o caso das migrações rural-urbanas, ocasionadas paralelamente à incorporação de modernas tecnologias, poupadoras de mão de obra. Em suma, cabe dizer que a tecnologia dominou a agricultura, buscando o aumento da produtividade das propriedades por meio do uso de maquinários e pacotes tecnológicos (insumos), reduzindo assim a necessidade de mão de obra, o que resultou em intenso êxodo rural.

Conforme destaca Schneider (1994), esse deslocamento de expressivo número de pessoas para o meio urbano ocorrido no Brasil pode ser explicado pelo reflexo das transformações ocorridas na esfera da organização da produção e da realocação de recursos econômicos ocorridos naquele momento.

A respeito disso, Balsadi e Silva (2008), salientam que, esse processo de modernização da agricultura acabou "destruindo" empregos agrícolas devido à fatores como, crescente especialização na produção das principais commodities, mecanização que se aprofundou na agricultura de grande escala, a qual empregava poucos trabalhadores, crescente importância da terceirização e prestação de serviços na agricultura, entre outras razões.

Ainda de acordo com Schneider (1994), na década de 1970 cerca de 16 milhões de brasileiros deixaram o meio rural. No caso do Rio Grande do Sul, aproximadamente 1,2 milhões de gaúchos seguiram este mesmo destino. Estes dados, atrelados a outras variáveis, levam-nos a crer que a modernização da agricultura foi um fator de aceleração da saída das pessoas do meio rural rumo ao meio urbano.

Deste modo, apesar das relativas controvérsias na delimitação do espaço rural versus espaço urbano, conforme mostra o trabalho de Veiga (2002), estudos como o de Camarano e Abramovay (1999) e Anjos e Caldas (2005) apontam para um acelerado processo de redução da população rural brasileira, sobretudo a partir dos anos 60. Este processo transformou o Brasil de uma sociedade predominantemente rural para uma sociedade urbana.

Atualmente, ao analisarmos dados estatísticos referentes à população, é possível constatar que esse deslocamento de pessoas, iniciado, sobretudo, a partir de 1960, permanece até os dias atuais, mesmo que em menor proporção, porém transforma-se, nas últimas décadas, de um êxodo rural "generalizado" para um 
processo mais "seletivo". (CAMARANO; ABRAMOVAY, 1998; ANJOS; CALDAS, 2005; FROELICH, et al., 2011).

Em outras palavras, Froehlich et al. (2011) explicam que até aproximadamente a década de 1980 o êxodo rural apresentava-se de forma bastante intensa, porém uniforme, quanto ao sexo e idade, ou seja, toda a família deixava o meio rural rumo aos centros urbanos, motivada principalmente pelas condições adversas ocasionadas pela modernização conservadora da agricultura, combinada com o acelerado processo de industrialização do país e a demanda por mão de obra barata no meio urbano. Após esse período, a migração remete às cidades a população mais jovem, ou seja, em idade ativa e altamente produtiva, deixando para trás uma população envelhecida, e, em alguns casos ainda, com predominância feminina, acelerando o fenômeno de envelhecimento e cristalizando a masculinização da população rural (CAMARANO; ABRAMOVAY, 1998; ANJOS; CALDAS, 2005).

Somada à migração dos jovens, a evolução das variáveis demográficas, especialmente as quedas nas taxas de fecundidade entre as mulheres e o aumento na expectativa de vida, acentuam ainda mais a tendência ao envelhecimento populacional rural em períodos mais recentes.

A partir dos aspectos mencionados, este artigo tem como objetivo traçar um panorama das principais características sociodemográficas, da população rural da microrregião e especialmente do município de Frederico Westphalen, norte do estado do Rio Grande do Sul, bem como discutir as implicações destas características para o meio rural local. Contudo, destaca-se já de antemão as limitações do presente estudo devido à complexidade de se trabalhar com o recorte do rural, visto que a delimitação do espaço rural e urbano envolve questões políticas e não apenas as características que determinam essa condição.

A escolha da referida região de estudo deu-se fundamentalmente a partir de critérios objetivos, indicados por meio de dados secundários que por sua vez estariam vinculados aos elementos conceituais. Frederico Westphalen é o município mais representativo, dentre os demais que compõe a microrregião, em basicamente duas características, as quais contribuíram para sua escolha. A primeira diz respeito ao baixo percentual de pessoas residindo no meio rural (apenas 19\%) e a segunda característica refere-se ao fato de a maior parte dos estabelecimentos agropecuários serem "chefiados" por pessoas com idade superior a 55 anos $(38,9 \%)$, e apenas $0,43 \%$ dos estabelecimentos por pessoas jovens, com idade igual ou inferior a 25 anos.

Para a construção do trabalho, utilizou-se de dados secundários, os quais foram obtidos por meio dos censos demográficos (1970, 1980, 1991, 2000 e 2010) do Instituto Brasileiro de Geografia e Estatística (IBGE), bem como dos censos agropecuários (2007 e 2017).

\section{REFERENCIAL TEÓRICO E CONCEITUAL}

\subsection{AS QUESTÕES DEMOGRÁFICAS E SUAS RELAÇÕES COM O DESENVOLVIMENTO ECONÔMICO}

As questões demográficas, especialmente no que tange aos seus impactos e desafios para o crescimento econômico dos países, historicamente impulsionam acalorados debates, predominantemente por economistas e demógrafos ao longo do tempo. Ainda ao final do século XVIII, estas questões já eram alvo de discussões filosóficas entre o iluminista Jean Antonio Nicholas Caricot, Marquês de Condorcet, e o pastor anglicano Thomas Robert Malthus (GODOI, 2014). 
Antecipa-se, de antemão, que as discussões iniciais a respeito do tema tinham por base a preocupação com a explosão populacional, especialmente nos espaços urbanos. Na concepção dos pensadores Malthus e Condorcet, o crescimento populacional era visto sobre duas perspectivas. De um lado, através de uma visão otimista, Condorcet acreditava que o crescimento populacional dar-se-ia de forma equilibrada, uma vez que as taxas de fecundidade e mortalidade se reduziriam ao longo do tempo. Por outro lado, através de um viés mais pessimista, Malthus pensava que o crescimento populacional seria um fator limitante para o desenvolvimento econômico, tendo em vista que a população se encaminhava para um crescimento acima de sua capacidade de abastecimento (KIELING, 2009; GODOI, 2014).

No que diz respeito aos estudos realizados no âmbito nacional acerca das questões demográficas, cabe destacar algumas instituições e institutos que têm dedicado parte de suas pesquisas a estas questões, tais como o Instituto de Pesquisa Econômica Aplicada (IPEA), a Associação Brasileira de Estudos Populacionais (ABEP), o Centro de Desenvolvimento e Planejamento Regional (Cedeplar) da Universidade Federal de Minas Gerais (UFMG), bem como a própria Fundação de Economia e Estatística (FEE) e o Instituto Brasileiro de Economia e Estatística (IBGE).

Tratando-se do IPEA, os estudos, em sua maioria, têm dado ênfase principalmente às inter-relações existentes entre as dinâmicas demográficas e econômicas e as demandas por políticas públicas. Desde que o IPEA foi fundado, em 1964, muitas mudanças no que tange à dinâmica populacional e demográfica brasileira foram ocorrendo. Inicialmente, coincidindo com sua fundação, a população crescia às mais elevadas taxas já verificadas.

Deste modo, conforme indica Camarano (2014), foi a partir de meados do século passado que estes estudos passaram a ganhar maior força e visibilidade por planejadores e líderes políticos, bem como cientistas sociais. Para estes pensadores, o rápido crescimento populacional reduziria o potencial de crescimento econômico dos países, principalmente daqueles menos desenvolvidos, como o caso do Brasil. Recentemente, após aproximadamente 50 anos de fundação do IPEA, a população se encaminha para uma redução relativa nas taxas de crescimento.

Neste sentido, os estudos referentes ao envelhecimento populacional bem como suas consequências têm sido alvo de intensas preocupações e indagações. $O$ referido tema ganhou relevância, tendo em vista que o aumento no contingente de pessoas idosas reflete significativamente no crescimento econômico, no mercado de trabalho e nas demandas por políticas públicas, especialmente aquelas voltadas à previdência social.

A esse respeito, Camarano (2014) destaca que, diante do fenômeno de envelhecimento populacional surgem determinadas restrições no médio e longo prazo para o crescimento econômico, tendo em vista que em algumas situações as gerações mais velhas são menos produtivas e mais resistentes à incorporação de mudanças tecnológicas. Sendo assim, o envelhecimento da força de trabalho pode ocasionar crescimento mais lento da produtividade.

\subsection{CARACTERÍSTICAS GERAIS DA POPULAÇÃO E TENDÊNCIAS DEMOGRÁFICAS NO BRASIL E NO RIO GRANDE DO SUL}

No Brasil, no que tange às questões demográficas, as mudanças e transformações ocorreram especialmente a partir da década de 1950. Em linhas gerais, Alves e Cavenaghi (2012) ressaltam que essas transformações estão relacionadas de alguma forma entre si e referem-se especialmente ao crescimento populacional, declínio nas taxas de fecundidade e mortalidade, entre outras questões. 
Em relação ao crescimento populacional, os mesmos autores indicam que a população brasileira cresceu aproximadamente 20 vezes entre 1872 e 2010, atingindo o máximo de crescimento nas décadas de 1950 e 1960 e reduzindo o ritmo a partir de 1970, sendo que, deverá continuar crescendo lentamente até 2030, para, em seguida, fazer a transição para o decrescimento.

A respeito da população rural e urbana, houve um significativo acréscimo entre os residentes do meio urbano, os quais representavam um total de 19 milhões, em 1950, passando a representar 161 milhões, em 2010, havendo assim um crescimento percentual de $36 \%$ para $84 \%$ da população urbana em relação ao total da população (ALVES; CAVENAGHI, 2012).

Uma terceira transformação consiste no declínio das taxas de mortalidade e natalidade. Estes indicadores fazem com que o Brasil deixe de apresentar uma estrutura etária jovem, passando para uma estrutura adulta e se encaminhando para uma estrutura etária envelhecida.

A respeito disso, Ávila e Machado (2015), ressaltam que este processo de transição demográfica sempre inicia com a queda das taxas de mortalidade, e, portanto, com o aumento da esperança de vida, e depois de um determinado período de tempo, que varia entre os países, as taxas de natalidade também iniciam um processo de declínio, ocasionando redução nas taxas de crescimento populacional como um todo e mudanças na estrutura etária no sentido do envelhecimento. A diferença entre estes dois fenômenos gera num primeiro momento crescimento populacional, tendo em vista que as taxas de fecundidade começam a declinar somente um tempo após a mortalidade.

Em síntese, o envelhecimento populacional é uma consequência da transição demográfica. Conceitualmente abordando o termo, Carvalho e Garcia (2003) destacam que o mesmo refere-se a maior proporção de idosos em relação ao conjunto total da população. Conforme projeções de Alves e Cavenaghi (2012), a partir do ano de 2040 haverá no Brasil mais idosos do que jovens.

De acordo com dados do Banco Mundial (2011), em 1980 os índices de envelhecimento eram iguais a 10,5, aumentando para 18,3 e 26,7 nos anos de 2000 e 2010, respectivamente. Além disso, a tendência é que esses índices aumentem ainda mais, ou seja, em 2050 essa proporção poderá ser de 100 crianças para 172,7 idosos.

Em suma, taxas de natalidade e mortalidade menores transformam a estrutura etária da população. De acordo com o IBGE, a taxa de mortalidade referese à um índice demográfico obtido pela relação entre o número de mortos de uma população e um determinado espaço de tempo, normalmente, um ano.

A evolução nos níveis de mortalidade pode ser avaliada por meio da esperança de vida ao nascer, que constitui um indicador síntese dessa variável, sendo expresso pelo número de anos esperados que se viva um recém-nascido estando este exposto às taxas de mortalidade observadas em uma determinada população em dado período.

Conforme dados do IBGE, na década de 1980 a expectativa de vida do brasileiro era igual 62,52 anos, aumentando para 73,76 em 2010. Isso significa dizer que houve um acréscimo de 11,24 anos em apenas 30 anos. As principais causas da redução nos níveis de mortalidade dizem respeito ao avanço no sistema de saúde pública e previdência social, além de avanços na indústria química farmacêutica que auxiliaram na redução e controle de diversas doenças.

Em relação às taxas de fecundidade totais, de acordo com a definição do IBGE, as mesmas referem-se a uma estimativa do número médio de filhos que uma mulher apresenta ao longo da vida durante sua fase fértil ou período reprodutivo, 
sendo calculada pela razão entre o número de nascimentos e o número de mulheres em idade fértil, e representada pelo período reprodutivo entre 15 a 49 anos.

Nas últimas décadas, evidenciou-se grande redução nos níveis desta variável, o que tem gerado uma transição nos níveis de fecundidade. As taxas de fecundidade entre as brasileiras, representado por 6,2 filhos por mulher em 1940, reduziram-se para 1,9 filhos por mulher em 2010, devendo chegar a 1,7 filhos por mulher em 2020.

Para Carvalho e Wong (2008), a fecundidade é o que impacta de forma mais significativa na estrutura etária populacional. No caso brasileiro, a acentuada queda nos níveis deste indicador ao longo das décadas foi o principal fator desencadeador da redução nas taxas de crescimento populacional, conforme Zuanazzi (2015) ressalta, o qual passou de 3,04\% em 1960 para 1,05\% em 2008, e, de acordo com projeções, poderá chegar a valor negativo em 2050, representado por -0,291\%.

No Brasil, o processo de transição, ou seja, a passagem de elevados níveis de fecundidade para níveis inferiores tem acontecido de forma bastante rápida comparativamente aos demais países do mundo. Neste sentido, Wong e Carvalho (2006) indicam que a maior parte dos países europeus levou quase um século para completar essa mesma transição. Suécia e Inglaterra, por exemplo, levaram cerca de seis décadas para diminuir $50 \%$ de seus níveis de fecundidade, enquanto que o Brasil experimentou um declínio similar em apenas um quarto de século. Esta situação reflete na queda da fecundidade que vem se mostrando generalizada em todo o território brasileiro, embora as desigualdades socioeconômicas tenham adiado, em parte, o início desse processo nas regiões menos desenvolvidas.

Analisando esta variável por situação de domicílio, Godoi (2014) com base nos dados do IBGE, evidencia que nas últimas décadas as diferenças entre mulheres residentes no meio urbano e no meio rural reduziram-se. Em 1970 a diferença era de 3,1 filhos, passando para 1,31 em 2000 e 0,84 filhos em 2010. Ou seja, no ano de 2000 as taxas de fecundidade entre as mulheres residentes no meio urbano equivaliam a 2,18 e no meio rural, 3,49 filhos por mulher. Em 2010, houve uma redução, passando a representar 1,79 , no meio urbano e 2,63 filhos por mulher no meio rural.

Em relação às regiões brasileiras, Zuanazzi (2015) indica que a Região Sul e a Sudeste, alcançaram taxas de fecundidade abaixo dos níveis de reposição no início dos anos 2000, com uma tendência de redução acelerada. Enquanto o país, como um todo, baixou desse patamar somente em meados daquela década.

A taxa de reposição populacional, como o próprio nome indica, corresponde a reposição da população e está intimamente relacionada com a taxa de fecundidade. Segundo o IBGE, a média de fecundidade deve ser de 2,1, uma vez que um casal é formado por duas pessoas, o que equilibra o número de habitantes. Em outras palavras, para assegurar a reposição populacional, o número de filhos por mulher deve ser superior a 2,1.

Contudo, a tendência de diminuição da fecundidade permaneceu em todas as unidades federativas, conforme apontam os dois últimos censos e as Pesquisas Nacionais por Amostra de Domicílios (PNADs). De acordo com Zuanazzi (2015), no caso do Rio Grande do Sul, em 2010, o estado apresentava taxa de fecundidade entre as mulheres de 1,75 , o que o colocava em quinto lugar no ranking de menor valor entre todos os estados brasileiros, atrás apenas de São Paulo, Rio de Janeiro, Santa Catarina e Distrito Federal.

Considerando as taxas de fecundidade via Regiões Funcionais de Planejamento (RFP) do estado do Rio Grande do Sul, o mesmo autor não encontrou diferenças significativas em relação à taxa de fecundidade, embora a região da Serra Gaúcha apresente a menor taxa $(1,50)$ e Fronteira Oeste e Litoral, as maiores, 
respectivamente, 1,96 e 1,94. As RFP que representam o Norte do Rio Grande do Sul, local de realização deste estudo, apresentaram taxas de fecundidade igual a 1,79 e 1,76 , sendo estas superiores à média estadual.

Já ao verificar a taxa de fecundidade entre as mulheres gaúchas separadas por raça, Zuanazzi (2015) evidenciou que as mulheres declaradas brancas apresentaram taxas abaixo do nível de reposição em 2010. Já as gaúchas negras e pardas encontravam-se ligeiramente acima desse nível, e as indígenas, embora não tenham apresentado tamanho amostral suficiente, estavam em um patamar de mais de três filhos por mulher.

O autor explica esses resultados indicando que, essa relação está associada ao nível salarial e educacional, que é maior, em média, entre brancos do que entre negros e pardos, que, por sua vez, possuem níveis maiores do que os indígenas. Entretanto, cabe ainda salientar que entre 2000 e 2010 houve redução da fecundidade entre todas as raças, seguindo o padrão verificado no total da população.

Tratando-se das taxas de fecundidade no Rio Grande do Sul por situação de domicílio, Zuanazzi (2015), observa que, em 2010, as moradoras de áreas rurais e as de áreas urbanas apresentavam, respectivamente, taxas de fecundidade igual ou abaixo do nível de reposição, sendo representado por 2,01 para as gaúchas residentes no meio rural, frente a 1,70 das residentes em áreas urbanas.

Esse valor mais elevado para as residentes no meio rural pode estar relacionado com as diferenças nas rendas médias entre as mulheres residentes no meio urbano e as residentes no meio rural, que eram 567 e 437 reais, respectivamente. Além disso, esse maior número de filhos entre as residentes do meio rural pode estar relacionado ao auxílio dos filhos na realização do trabalho, especialmente quando se refere à agricultura familiar, tendo em vista que os mesmos são introduzidos no trabalho familiar desde cedo, desempenhando tarefas úteis, como limpeza, plantio, colheita e cuidado com os irmãos menores (ZUANAZZI, 2015).

Com base nos dados apresentados, observa-se que, apesar das taxas de fecundidade entre as mulheres residentes no meio rural permanecerem maiores comparativamente às mulheres residentes no meio urbano, a redução ocorreu de forma bastante significativa, sobretudo, entre os anos de 2000 e 2010.

Tratando-se especialmente do meio rural, Maia e Buanain (2015) ressaltam que, simultaneamente à redução no número de filhos reduziu-se também a disponibilidade de mão de obra para a atividade agrícola. Sobre esta questão, os dados dos censos agropecuários apontam que desde 1980 se observa uma redução no número médio de pessoas por família ocupadas na agricultura. Em 1980 eram 4,10; passando para 4,03 em 1985; 3,65 em 1996; e 3,20 em 2006.

Essa diminuição no número total de pessoas ocupadas sinaliza uma tendência importante em relação às ocupações na agricultura, embora o número total de estabelecimentos agropecuários tenha apresentado uma tendência de aumento. Ou seja, mesmo gerando mais estabelecimentos agropecuários (avanço sobre o Cerrado e Amazônia e também por conta dos assentamentos de reforma agrária) os dados indicam que o cenário é de núcleos familiares menores e menos pessoas ocupadas na agricultura.

A esse respeito, Silvestro et al. (2001) indicam que o reduzido número de pessoas por famílias ocupadas na agricultura, sobretudo jovens, acaba ocasionando problemas semelhantes ao que é constatado na Europa, que é o destino comprometido de grande quantidade de propriedades familiares devido à ausência de sucessores para dar continuidade às propriedades, especialmente as familiares.

Por fim, cabe destacar ainda que, paralelamente a evolução nas variáveis demográficas, especialmente, redução no número de filhos devido à queda nas taxas de fecundidade somada à migração no sentido rural/urbano da população jovem e em 
idade ativa, emergem desafios para a manutenção das propriedades familiares no médio e longo prazo. A dinâmica demográfica da população rural da microrregião e do município de Frederico Westphalen será retratada na seção seguinte.

\section{ANÁLISE DOS RESULTADOS}

\subsection{DINÂMICA DEMOGRÁFICA DA POPULAÇÃO RURAL NA MICRORREGIÃO E NO MUNICÍPIO DE FREDERICO WESTPHALEN}

A microrregião de Frederico Westphalen ${ }^{3}$ é uma das 35 microrregiões do estado do Rio Grande do Sul, composta por 27 municípios e uma área total de $5.182,529 \mathrm{~km}^{2}$, pertencendo à Mesorregião Noroeste Rio-Grandense. Em 2010, data do último censo demográfico, a população era 174.664 habitantes. A FEE estima que em 2015 essa população perfazia um total de 176.944 pessoas, representando um pequeno acréscimo em relação ao último censo demográfico.

Em relação ao município de Frederico Westphalen, o mesmo localiza-se geograficamente ao norte do estado do Rio Grande do Sul, possui área total de 264,56 $\mathrm{km}^{2}$ e densidade demográfica igual a 109,04 hab $/ \mathrm{km}^{2}$, demonstrando que o município apresenta esta variável alta, comparativamente ao estado do Rio Grande do Sul que possui média de $37,96 \mathrm{hab} / \mathrm{km}^{2}$,conforme indicam os dados do censo demográfico de 2010.

De acordo com o último censo demográfico, a população municipal era de 28.843 habitantes. A FEE estima que em 2015 a população passou a ser representada por um total de 30.800 habitantes, indicando que houve um acréscimo considerável em relação ao censo demográfico de 2010. A evolução populacional nos últimos 40 anos para a microrregião e o município é apresentada na Tabela 1.

Tabela 1 - Dinâmica populacional da microrregião e do município de Frederico Westphalen no período de 1970 a 2010.

\begin{tabular}{|c|c|c|c|c|c|c|c|}
\hline & & \multicolumn{6}{|c|}{ Ano do Censo Populacional } \\
\hline & & 1991 & $\%$ & 2000 & $\%$ & 2010 & $\%$ \\
\hline \multirow{3}{*}{$\frac{o}{\frac{0}{0}}$} & Urbana & 62.682 & 31,4 & 83.704 & 45,3 & 93.248 & 53,4 \\
\hline & Rural & 137.123 & 68,6 & 101.058 & 54,7 & 81.357 & 46,6 \\
\hline & Total & 199.805 & 100 & 184.713 & 100 & 174.664 & 100 \\
\hline \multirow{3}{*}{$\frac{\dot{U}}{\mathrm{C}}$} & Urbana & 14.766 & 58,2 & 20.433 & 76,4 & 23.333 & 80,9 \\
\hline & Rural & 10.169 & 40,8 & 6.326 & 23,6 & 5.510 & 19,1 \\
\hline & Total & 24.935 & 100 & 26.759 & 100 & 28.843 & 100 \\
\hline
\end{tabular}

Fonte: IBGE (Censos Populacionais de 1991, 2000 e 2010). Elaborada pelos autores.

3 Os municípios que integram a microrregião são: Alpestre, Ametista do Sul, Caiçara, Constantina, Cristal do Sul, Dois Irmãos das Missões, Engenho Velho, Erval Seco, Frederico Westphalen, Gramado dos Loureiros, Iraí, Liberato Salzano, Nonoai, Novo Tiradentes, Novo Xingu, Palmitinho, Pinheirinho do Vale, Planalto, Rio dos Índios, Rodeio Bonito, Rondinha, Seberi, Taquaruçu do Sul, Três Palmeiras, Trindade do Sul, Vicente Dutra e Vista Alegre. Destes, Frederico Westphalen é considerado o principal centro urbano ou o "município polo regional", seja econômico ou de atração populacional. 
A população total da microrregião de Frederico Westphalen apresentou diminuição no número total de habitantes ao longo do período analisado. Em relação às maiores perdas populacionais, as mesmas estão nas áreas rurais, onde praticamente todos os municípios apresentaram diminuição de suas populações. Tratando-se da microrregião de Frederico Westphalen, entre as décadas de 1991 e 2000 houve uma redução na participação da população rural de aproximadamente 13,9 pontos percentuais.

Estes dados demonstram que, apesar de tratar-se de uma região com grande contingente de pessoas residentes no meio rural comparativamente a outras regiões do estado, o processo de esvaziamento demográfico rural também se faz presente neste local. Em contrapartida, o meio urbano apresentou um acréscimo no contingente populacional durante todo o período analisado.

Entretanto, apesar da maior parte da população residir no meio urbano (53,4\%), bem como ter ocorrido redução na população rural e acréscimo na população urbana ao longo do período, a microrregião se mantem com o maior número de municípios com população predominantemente rural, sendo esta uma característica peculiar da região.

Dentre os municípios com maior percentual de pessoas residindo no meio rural, destacam-se os municípios de Pinheirinho do Vale (79,6\%); Rio dos Índios (79,1\%); Liberato Salzano (77,6\%); Novo Tiradentes $(71,3 \%)$ e Caiçara $(68,6 \%)$. Por outro lado, os municípios de Frederico Westphalen (80,9\%); Rodeio Bonito (75, $1 \%$ ) e Nonoai $(75,1 \%)$ são aqueles que apresentam maior percentual da população residente no meio urbano.

Em relação ao município de Frederico Westphalen, o mesmo é predominantemente urbano, ou seja, 23.333 habitantes $(80,9 \%)$ residem neste meio (o urbano), e apenas 5.510 habitantes $(19,1 \%)$ residem no meio rural.

No que se refere à população dividida por local de residência, houve considerável redução na população rural nas últimas três décadas, havendo um decréscimo de aproximadamente $50 \%$ no percentual de pessoas residentes no meio rural entre os anos de 1991 e 2010 , passando de 10.169 para 5.510 habitantes.

Em contrapartida, entre os anos de 1991 e 2010 o município apresentou crescimento populacional, sendo um dos únicos municípios da microrregião a apresentar esta característica, conforme destacado anteriormente. Dentre outros, um dos fatores que contribui para essa realidade é a migração de pessoas de outros municípios para Frederico Westphalen, tendo em vista que se trata de um município polo regional, fazendo com que muitos busquem nele melhores oportunidades de trabalho e estudos, especialmente a população mais jovem, haja vista que o município conta com unidades de ensino ${ }^{4}$ referências. Ainda se tratando das questões populacionais, a dinâmica populacional separada por sexo é apresentada na Tabela 2.

\footnotetext{
${ }^{4}$ Universidade Regional Integrada do Alto Uruguai e das Missões (URI), da Universidade Federal de Santa Maria (UFSM), do Instituto Federal Farroupilha (IFF) e da Universidade Estadual do Rio Grande do Sul (UERGS).
} 
Tabela 2 - Dinâmica populacional total e rural (por sexo) na microrregião e no município de Frederico Westphalen no período de 1991 a 2010.

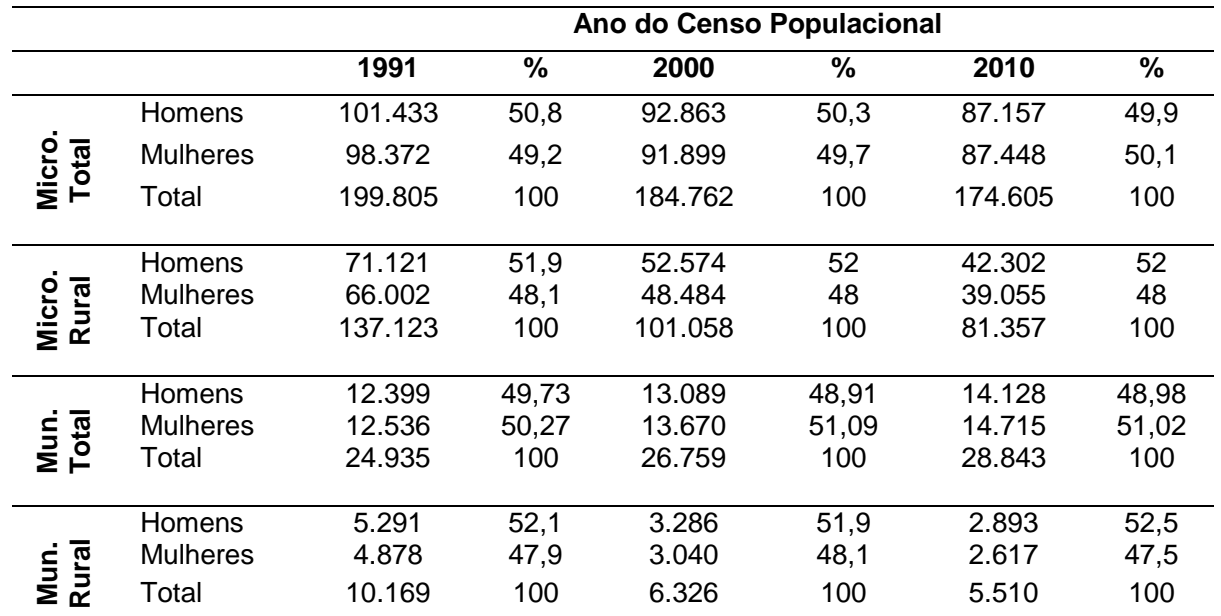

Fonte: IBGE (Censos Populacionais de 1970, 1980, 1991, 2000 e 2010). Elaborada pelos autores.

No caso da microrregião de Frederico Westphalen, o percentual de homens sobre a população total manteve-se superior ao percentual de mulheres entre as décadas de 1991 e 2000, representadas por 50,8 e 50,3\%, respectivamente. Em 2010, houve mudanças, visto que o percentual de mulheres se tornou superior ao percentual de homens, representando $50,1 \%$ da população total. Cabe mencionar ainda que a maior participação de mulheres na população total se deve a maior sobrevivência delas (expectativa de vida superior comparativamente aos homens). Essa maior sobrevivência das mulheres ocorre em todas as regiões do Brasil, por distintas razões, dentre elas, o maior cuidado com a saúde. De acordo com o IBGE, no Brasil, as mulheres vivem em média, quase sete anos a mais que os homens.

Tratando-se especificadamente da população rural da microrregião, o percentual de homens, mesmo não apresentando variações significativas entre 1991 e 2010 se manteve superior ao percentual de mulheres nas três décadas. Anjos, Caldas e Pollnow (2014), analisando o processo de masculinização no Rio Grande do Sul por estratos etários, constaram que a população feminina rural supera a masculina em apenas dois estratos etários de idade (70- 79 anos; e 80 e mais) devido à maior longevidade.

Já no caso do município de Frederico Westphalen, apesar de pouco representativa a diferença, o percentual de mulheres predominou em relação ao percentual de homens sobre a população total em todo o período analisado (1991 a 2010). Sendo que, as maiores diferenças por sexo encontram-se entre os residentes do meio rural. Em termos percentuais, os homens representam $52,5 \%$ da população total rural no ano de 2010. Esses dados evidenciam que o processo de masculinização, ou seja, população masculina em número superior a população feminina está presente.

Anjos, Caldas e Pollnow (2014), associam o processo de masculinização da região Sul do país a um conjunto de fatores, tais como, a precariedade estrutural das 
localidades rurais, o advento das tecnologias da Revolução Verde, as desigualdades de gênero, entre outros.

Em relação à estrutura etária da população ${ }^{5}$, de acordo com dados do censo demográfico de 2010, tem-se observado uma menor proporção de crianças e jovens e uma maior participação de adultos e idosos na composição total da população, o que tem ocasionado elevados índices de envelhecimento ${ }^{6}$, conforme apresentado na Tabela 3:

Tabela 3: Estrutura etária da população total e rural da microrregião e do município de Frederico Westphalen (RS) no período de 1991 a 2010.

\begin{tabular}{|c|c|c|c|c|c|c|c|}
\hline & & \multicolumn{6}{|c|}{ Ano do Censo Populacional } \\
\hline & & 1991 & $\%$ & 2000 & $\%$ & 2010 & $\%$ \\
\hline \multirow{4}{*}{ 遂 $\frac{\pi}{0}$} & Menos de 15 & 69.178 & 34,6 & 52.433 & 28,4 & 37.029 & 21,2 \\
\hline & 15 a 64 anos & 120.630 & 60,4 & 118.777 & 64,3 & 119.495 & 68,4 \\
\hline & 65 ou mais & 9.997 & 5 & 13.552 & 7,3 & 18.083 & 10,4 \\
\hline & $\mathrm{IE}^{\star}$ & \multicolumn{2}{|c|}{5,0} & \multicolumn{2}{|c|}{7,3} & \multicolumn{2}{|c|}{10,4} \\
\hline \multirow{4}{*}{ 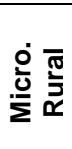 } & Menos de 15 & 48.472 & 43,4 & 29.377 & 29,1 & 17.637 & 21,7 \\
\hline & 15 a 64 anos & 56.713 & 50,7 & 64.404 & 63,7 & 54.997 & 67,7 \\
\hline & 65 ou mais & 6.643 & 5,9 & 7.276 & 7,2 & 8.723 & 10,6 \\
\hline & $\mathrm{IE}^{\star}$ & \multicolumn{2}{|c|}{5,9} & \multicolumn{2}{|c|}{7,2} & \multicolumn{2}{|c|}{10,6} \\
\hline \multirow{3}{*}{ 宅 } & $\begin{array}{l}\text { Menos de } 15 \\
15 \text { a } 64 \text { anos }\end{array}$ & $\begin{array}{c}8.087 \\
15.639\end{array}$ & $\begin{array}{l}32,5 \\
62,8\end{array}$ & $\begin{array}{c}6.085 \\
17.758\end{array}$ & $\begin{array}{l}23,8 \\
69,5\end{array}$ & $\begin{array}{c}5.790 \\
20.540\end{array}$ & $\begin{array}{l}20,1 \\
712\end{array}$ \\
\hline & 65 ou mais & 1.209 & 4,8 & 1.699 & 6,7 & 2.513 & 8,7 \\
\hline & IE & \multicolumn{2}{|c|}{4,8} & \multicolumn{2}{|c|}{6,7} & \multicolumn{2}{|c|}{8,7} \\
\hline \multirow{4}{*}{ 方売 } & Menos de 15 & 3.453 & 34 & 1.691 & 26,7 & 1.056 & 19,2 \\
\hline & 15 a 64 anos & 6.224 & 61,2 & 4.206 & 66,5 & 3.835 & 69,6 \\
\hline & 65 ou mais & 492 & 4,8 & 429 & 6,8 & 617 & 11,2 \\
\hline & IE & \multicolumn{2}{|c|}{4,8} & \multicolumn{2}{|c|}{6,8} & \multicolumn{2}{|c|}{11,2} \\
\hline
\end{tabular}

Fonte: Instituto Brasileiro de Geografia e Estatística (IBGE); Atlas do Desenvolvimento Humano no Brasil (2015). Elaborado pelos autores. *Índice de Envelhecimento.

No que diz respeito à estrutura etária da população total na microrregião de Frederico Westphalen, observa-se que tem ocorrido uma redução considerável na população com até 15 anos de idade e um acréscimo na população de 65 anos ou mais. Estas alterações na estrutura etária da população fizeram com que o índice de envelhecimento aumentasse em mais de $100 \%$, passando de 5 idosos para cada 100 jovens em 1991 para 10,4 idosos para cada 100 jovens, em 2010.

Em relação aos índices de envelhecimento presentes especificamente no meio rural da microrregião de Frederico Westphalen, os dados demonstram que nas três últimas décadas os mesmos praticamente duplicaram. Em contrapartida, houve uma queda de mais de $50 \%$ no número de crianças no mesmo período, as quais representavam 43,4\% em 1991, passando a representar 21,7\% em 2010.

No caso do município de Frederico Westphalen, evidenciam-se resultados semelhantes, no qual o número de pessoas com idade superior a 65 anos também

${ }^{5}$ A população em idade ativa é composta por adultos de 15 a 64 anos sendo considerada potencialmente produtiva, com isso, a taxa de dependência é obtida pela soma das crianças (0 a 14 anos) e idosos (acima de 65 anos), dividida pela população adulta. De maneira arbitrária, são considerados como dependentes as crianças e os idosos (WONG; CARVALHO, 2006).

${ }^{6} \mathrm{O}$ índice de envelhecimento é calculado pela razão entre a população de 65 anos ou mais de idade em relação à população total. 
sofreu um incremento, passando de 4,8 idosos para cada 100 jovens em 1991 para 8,7 idosos para cada 100 jovens, em 2010.

Ao observarmos a estrutura etária da população rural do município em análise, os dados apontam que o envelhecimento neste meio é ainda mais intenso. Como se pode notar, houve um acréscimo considerável na população de 65 anos ou mais, sobretudo entre as décadas de 2000 e 2010, período este em que passou de 429 para 617 idosos. O resultado deste acréscimo no número de pessoas idosas é um incremento nos índices de envelhecimento da população rural, os quais passaram de $4,8 \%$ para $11,2 \%$ em apenas três décadas. Por outro lado, o número de crianças, com idades inferiores a 15 anos, reduziu-se: em 1991 esse grupo etário representava $34 \%$ no total da população rural, passando a representar 19,2\% em 2010.

De acordo com estimativas populacionais referentes à população de 2015 , lançados recentemente pela FEE, as quais estão disponíveis por sexo e grupos etários, os dados indicam que em relação a Frederico Westphalen, a população idosa total do município (acima de 60 anos) representa atualmente um total de 4.709 pessoas, deste total, $2.606(55,3 \%)$ são mulheres. Deste modo, em relação à população total do município (30.800 habitantes), pode-se inferir que os idosos, acima de 60 anos, representam 15,3\% do total da população.

Fatores como aumento na expectativa de vida e redução nos níveis de fecundidade entre as mulheres contribuem para a redução no número de crianças e jovens e o acréscimo no número de idosos. Os dados referentes à evolução da esperança de vida ao nascer e taxa de fecundidade total do município de Frederico Westphalen são apresentados na Tabela 4.

Tabela 4: Esperança de vida ao nascer e fecundidade do município de Frederico Westphalen (RS) no período de 1991 a 2010.

\begin{tabular}{cccc}
\hline IDH e seus componentes & $\mathbf{1 9 9 1}$ & $\mathbf{2 0 0 0}$ & $\mathbf{2 0 1 0}$ \\
\hline Esperança de vida ao nascer (em anos) & 69,9 & 73,8 & 75,8 \\
Taxa de fecundidade total (filhos por mulher) & 2,7 & 2,2 & 1,6 \\
\hline
\end{tabular}

Fonte: Atlas do Desenvolvimento Humano no Brasil (2015).

No município de Frederico Westphalen, a esperança de vida ao nascer passou por um incremento de 2,0 anos na última década, de 73,8 anos, em 2000, para 75,8 anos, em 2010. Analisando todo o período (1991 a 2010), houve um acréscimo de 5,9 anos. A esperança de vida ao nascer é o indicador utilizado para compor a dimensão Longevidade do Índice de Desenvolvimento Humano (IDH).

Em relação às taxas de fecundidade, representadas pelo número de filhos por mulher, houve considerável redução no município nas três últimas décadas. Em 1991, as mulheres tinham, em média, 2,7 filhos, reduzindo para 1,6 em 2010. Este número $(1,6)$ demonstra que o número de filhos das mulheres frederiquenses está abaixo do nível de reposição representado por, 2,1 filhos.

A realidade é que, enquanto no passado as famílias dos agricultores eram numerosas, nos dias atuais observa-se o inverso. Esta situação configura uma relevante mudança demográfica representada pela diminuição nas taxas de fecundidade. Além da utilização dos métodos contraceptivos que contribuem para essa tendência de diminuição no número de filhos, há ainda uma revolução no papel social da mulher e nas relações de gêneros tradicionais, conforme ressaltam Camarano e Kanso (2010). Para as autoras, há atualmente uma maior integração das mulheres no mercado de trabalho e uma maior contribuição da renda das mesmas no total da renda das famílias brasileiras, alterando as relações tradicionais de gênero. 


\subsection{AS IMPLICAÇÕES DA DINÂMICA DEMOGRÁFICA PARA O MEIO RURAL LOCAL}

O Brasil passou por grandes transformações econômicas e sociais em meados do século $X X$, deixando de ser uma sociedade predominantemente rural para se tornar uma sociedade predominantemente urbana (ALVES; CAVENAGHI, 2012). Assim, apesar das relativas controvérsias na delimitação do espaço rural versus espaço urbano ${ }^{7}$, estudos ${ }^{8}$ apontam para um acelerado processo de redução da população rural brasileira, sobretudo a partir dos anos 60 .

De acordo com dados do Instituto Brasileiro de Geografia e Estatística (IBGE), o decréscimo da população rural brasileira é visível a cada contagem de censo populacional. Conforme o censo de 1991, a população que residia no meio rural era de aproximadamente 36 milhões de pessoas, diminuindo para aproximadamente 30 milhões em 2010. No caso do estado do Rio Grande do Sul, o cenário não é distinto. De acordo com dados do censo populacional de 1991, a população rural perfazia um total de aproximadamente 2,1 milhões de pessoas, reduzindo para aproximadamente 1,5 milhão em 2010, havendo um decréscimo em torno de $25 \%$. O município de Frederico Westphalen não foge do padrão federal e estadual, conforme apresentado na seção anterior.

Essa tendência de esvaziamento do meio rural brasileiro, mesmo em ritmo mais lento, permanece presente. Dentre os fatores que contribuem para esta realidade, Maia (2014) destaca fatores endógenos à estrutura familiar, tais como queda nas taxas de fecundidade e fragmentação das famílias, bem como redução no tamanho médio das mesmas, como já apontado anteriormente. Além destes, o autor cita os fatores exógenos, sobretudo a adoção de tecnologias na agricultura, que propiciaram liberação de mão-de-obra.

Nos países da América Latina este acontecimento ocorreu entre as décadas de 1960 e 1980, ocasionando migração para o meio urbano de aproximadamente 27 milhões de agricultores. Simultaneamente a este processo ocorrido no meio rural, acompanhava-se o processo de urbanização e industrialização no meio urbano, o qual se fundamentava na oferta abundante de mão de obra que era predominantemente rural.

Neste sentido, Singer (1987) considera que as migrações decorrem principalmente de mudanças nas regiões de origem dos migrantes. Entretanto, o autor salienta que, apesar da migração em massa dos agricultores e consequentemente a diminuição na população empregada em atividades agropecuárias a produção de alimentos não foi comprometida, devido as mudanças decorridas na base técnica da agricultura.

A respeito disso, pode- se inferir que ocorreu o inverso com a produção agrícola, conforme destacado anteriormente, a qual cresceu em ritmo bastante acelerado, amparada por elevados ganhos de produtividade. Face a esta dupla dimensão (crescimento da produção agrícola e redução da população empregada nestas atividades), Buainain et al. (2013) apontam esse "processo" como uma das sete teses de desenvolvimento rural ${ }^{9}$.

De acordo com a percepção dos autores, ocorre no país processo semelhante ao ocorrido na Argentina, o qual se caracteriza pelo desenvolvimento bastante exitoso dos setores produtivos agropecuários, porém concomitante a ele,

\footnotetext{
${ }^{7}$ Conforme mostra o trabalho de Veiga (2002).

${ }^{8}$ Camarano; Abramovay (1999) e Anjos; Caldas (2005).

${ }^{9}$ Para maiores informações consultar "Sete teses sobre o mundo rural brasileiro", de autoria de Antônio Márcio Buainain; Eliseu Alves; José Maria da Silveira; Zander Navarro (2013).
} 
ocorre um drástico decréscimo demográfico da população que vive no meio rural. Sob esta tese, se estabelece neste meio o predomínio da agricultura de larga escala, alta eficiência produtiva e tecnológica seguido do esvaziamento demográfico.

A respeito destas concepções teóricas é preciso destacar que um estudo de caso como este não permite confirmar ou refutar a (suposta) tese de Buainain et. al., (2014). No entanto, os dados secundários provenientes do IBGE em relação à microrregião e o município de Frederico Westphalen sinalizam para uma redução da população rural e das pessoas ocupadas na agricultura.

Em estudo realizado nos três estados do Sul do país, Anjos, Caldas e Pollnow (2014), apresentam algumas possíveis causas para a atual dinâmica demográfica, dentre elas destacam um universo de representações sociais extremamente negativas do ponto de vista da natureza desta atividade que pesam sobre a agricultura e o mundo rural. Condicionando assim, as escolhas, especialmente dos jovens rurais, cada vez menos propensos ao exercício da profissão.

Contudo, o deslocamento da população rural para o meio urbano tende a gerar contornos distintos entre as regiões, os níveis de qualificação, a idade entre outras questões. Neste sentido, Neves e Schneider (2015) corroboram afirmando que as mudanças não são homogêneas e acentuam-se especialmente e com maior intensidade em algumas regiões do país, como o caso da região Sul, e grupos sociais específicos, como os jovens que vivem no meio rural, os quais são mais propensos a migrarem para os centros urbanos à procura do primeiro emprego e de melhores oportunidades de renda.

De acordo com dados do IBGE, em 1991 residiam no meio rural brasileiro aproximadamente 7 milhões de jovens $\left(15\right.$ a 24 anos) ${ }^{10}$, reduzindo para aproximadamente 5 milhões em 2010, refletindo em uma redução de quase $27 \%$. No estado, de um total de aproximadamente 3,8 milhões de jovens em 1991, o número baixou para 2,3 milhões em 2010, representando uma redução de mais ou menos $39 \%$.

Por outro lado, simultaneamente à diminuição da população jovem houve um acréscimo no percentual da população idosa (acima de 60 anos) ${ }^{11}$ residente no meio rural. No caso brasileiro, de acordo com dados do IBGE, em 1991 a população idosa perfazia um total de aproximadamente 2,5 milhões de pessoas, aumentando para aproximadamente 3,3 milhões em 2010. Em relação à população idosa estadual, o acréscimo foi de aproximadamente $20 \%$, tendo em vista que de aproximadamente 217 mil pessoas, houve um aumento para 270 mil.

A esse respeito, Maia (2014) indica que houve acréscimo nos índices de envelhecimento da população rural brasileira, que passaram de 9,7\% em 1991 para $21,4 \%$ em 2010. Ou seja, o número médio de idosos para cada grupo de 100 jovens mais que dobrou, passando de 9,7 para 21,4.

As informações preliminares divulgadas pelo censo agropecuário (2017) não apenas confirmam estas mudanças na estrutura etária populacional, mas também revelam a emergência de "novas dinâmicas" do meio rural.

De acordo com os dados, as pessoas com 65 anos ou mais representam $21,4 \%$ dos moradores totais das áreas rurais, sendo que em 2006 representavam $17,52 \%$. Na faixa de 55 a 65 anos, houve aumento de quatro pontos percentuais, passando de $20 \%$ para $24 \%$. Uma segunda constatação a este respeito é de que aproximadamente $34 \%$ dos agricultores que estão à frente dos estabelecimentos

\footnotetext{
${ }^{10}$ Este recorte etário foi definido com base no IBGE que considera jovens as pessoas com idade entre 15 e 24 anos.

${ }^{11}$ Este recorte etário foi definido com base no IBGE que considera idosas as pessoas com idades acima de 60 anos.
} 
agropecuários possuem 60 anos ou mais, o que demonstra que a população rural envelheceu de fato.

O inverso ocorre com a população rural mais jovem, com idade entre 25 e 35 anos que teve seu contingente "encolhido", desde 2006, ocasião em que representava $13,56 \%$ da população rural total, passando a representar $9,48 \%$ de acordo com informações do censo agropecuário de 2017. O mesmo ocorreu com os jovens com menos de 25 anos, que representavam 1,9\% em 2006 passando a representar 1,2\% em 2017. No caso da região do Médio e Alto Uruguai, contexto empírico deste estudo, $4 \%$ dos produtores rurais tem menos de 30 anos, $61 \%$ entre 30 e 60 anos e $35 \%$ com mais de 60 anos.

Estes resultados demonstram que grande parte da população rural pode estar exercendo a atividade agropecuária associada ao recebimento da aposentadoria rural. Em tese, são agricultores que tendem a diminuir a capacidade produtiva e a produção agropecuária em razão de limitações de ordem física. Sendo assim, o envelhecimento das pessoas que dirigem as propriedades rurais brasileiras é um desafio para o país ampliar a capacidade de absorção tecnológica no Brasil, especialmente nas regiões rurais onde o índice de envelhecimento é superior, como é o caso da região Sul (MAIA, 2014).

Para Maia (2014), há dois aspectos fundamentais que contribuíram para que a região Sul, se encontrasse em estágio mais avançado de envelhecimento populacional. Em primeiro lugar, a região Sul apresentou a menor taxa de crescimento populacional no país (24\% entre 1991 e 2010), refletindo um estágio mais avançado de transição demográfica. Em segundo, as expressivas diferenças entre os ritmos de crescimento populacional urbano, representado por $42 \%$ positivo, e rural, representado por $28 \%$ negativo.

O mesmo autor (MAIA, 2014) acrescenta que a região Sul merece algumas considerações adicionais, não somente por ser uma região de presença marcante da agricultura familiar, mas também pela sua relevância em termos de produção agrícola do país. Contudo, apesar da região Sul apresentar, tradicionalmente, uma agricultura familiar dinâmica e bons indicadores de desenvolvimento humano, a migração rural urbano persiste, o que nos sugere que a migração não pode ser associada unicamente à pobreza presente no meio rural, mas também, por exemplo, à atração que a dinâmica socioeconômica urbana exerce sobre a atividade rural.

Em síntese, esta nova dinâmica demográfica (redução da participação dos grupos etários mais jovens e pelo crescimento daqueles mais idosos) representa no médio e longo prazo o comprometimento do processo de sucessão da atividade agrícola familiar, colocando em risco a sustentabilidade da mesma, bem como da própria sociedade rural como um todo, visto que os jovens constituem a força renovadora para o desenvolvimento desta forma social de organização do trabalho e da produção.

Ou seja, a migração dos jovens, atrelada à redução no número de filhos (discutido na seção anterior), acaba reduzindo os candidatos potenciais a permanecer na atividade agrícola. Diante destes fenômenos as perspectivas sucessórias na agricultura, especialmente a familiar, ficam restritas, com grandes chances dos poucos candidatos que restam a sucessão migrarem para o meio urbano após concluírem o ensino básico.

O trabalho de Spanevello et al. (2017) referente ao encaminhamento das propriedades familiares sem sucessores consiste no processo da venda da propriedade ou em deixar para os filhos, mesmo sem a certeza do destino que os filhos darão ao patrimônio. Segundo Matte et al. (2017), quando ocorre a venda, as propriedades não apenas trocam o gestor mas podem trocar também a função produtiva, podendo ser destinada para atividades não agrícolas, nos casos de uso 
para turismo rural ou lazer. Essa última alternativa possui chances mais significativas de se materializar quando os compradores são oriundos do meio urbano. Por outro lado, a propriedade, à medida que é comercializada para outros agricultores, tende a reduzir suas características familiares, levando a um possível aumento da concentração de terras.

Diante dessas questões, Neves e Schneider (2015) corroboram afirmando que há crescente preocupação em relação à viabilidade da agricultura familiar e à disponibilidade de força de trabalho no meio rural, tendo em vista que a reprodução deste tipo de agricultura é predominantemente endógena, de modo que a diminuição da população jovem reduz as perspectivas de reprodução dessa atividade econômica.

A preocupação com a viabilidade da agricultura familiar também é refletida nos dados preliminares divulgados pelo censo agropecuário de 2017 , visto que houve uma redução de $2 \%$ (103.484 estabelecimentos agropecuários) comparativamente com o censo de 2007.

Também se constatou uma redução de 1,5 milhões de pessoas ocupadas nos estabelecimentos agropecuários em 2017, passando a representar 15.036.978. A média de ocupados por estabelecimento também caiu de 3,2 pessoas, em 2006, para 3 pessoas, em 2017.

Considerando as discussões até aqui apresentadas, evidencia-se a ocorrência de importantes mudanças no padrão e dinâmica populacional das famílias e da sociedade como um todo ao longo do tempo. As quedas nos níveis de fecundidade e a permanente migração da população rural para as áreas urbanas, sobretudo da população jovem, são fatores fundamentais para a compreensão desta dinâmica.

\section{CONSIDERAÇÕES FINAIS}

Este trabalho teve como objetivo traçar um panorama das principais características sociodemográficas da população rural da microrregião e especialmente do município de Frederico Westphalen, norte do estado do Rio Grande do Sul, bem como discutir as implicações destas características para o meio rural local.

De modo geral, observa-se que a referida região não foge ao padrão nacional e estadual no que tange às mudanças demográficas, caracterizada pela redução da população jovem e acréscimo na população idosa. Estas características são ocasionadas, sobretudo pela redução nos níveis de fecundidade entre as mulheres que apresentou-se de forma gradual ao longo do período analisado. Tratando-se da população rural, estas características são ainda mais significativas, visto que o envelhecimento é intensificado pela migração seletiva, ou seja, da população mais jovem e em idade ativa.

Tais características, reforçadas pelos dados preliminares divulgados pelo censo agropecuário (2017) não apenas confirmam as mudanças na estrutura etária populacional, mas também revelam a emergência de "novas dinâmicas" do meio rural, sobretudo de que muitos agricultores podem estar exercendo a atividade agropecuária associada ao recebimento da aposentadoria rural. Nestes casos, são agricultores que tendem a diminuir a capacidade produtiva e a produção agropecuária e as possíveis razões podem estar associadas às limitações de ordem física em virtude da idade avançada. 


\section{REFERÊNCIAS}

ALVES, J.E.D.; CAVENAGHI, S. Tendências demográficas, dos domicílios e das famílias no Brasil. Aparte: inclusão social em debate, Rio de Janeiro, 2012. Disponível em:

http://www.ie.ufrj.br/aparte/pdfs/tendencias_demograficas_e_de_familia_24ago12.pd f. Acesso em: 20 dez. 2016.

ANJOS, F.S.; CALDAS, N.V. O futuro ameaçado: o mundo rural face aos desafios da masculinização, do envelhecimento e da desagrarização. Ensaios FEE, Porto Alegre, v.26, n.1, p.661- 694, jun. 2005. Disponível em: http://www.scielo.br/pdf/cr/ v40n2/a469cr2481.pdf. Acesso em: 25 out. 2018.

ANJOS, F.S.; CALDAS, N.V; POLLNOW, G. E. Menos mulheres, menos jovens, mais incertezas: a transição demográfica no Brasil rural meridional. Extensão Rural, Santa Maria, v.21, n.2, abr./jun. 2014.

ATLAS do desenvolvimento humano no brasil. Rio de Janeiro, 2015. Disponível em: <http://www.atlasbrasil.org.br/2013/pt/perfil_m/frederico-westphalen_rs>. Acesso em: 05 dez. 2016.

ÁVILA, R.I.; MACHADO, A.M. Transição demográfica brasileira: desafios e oportunidades na educação, no mercado de trabalho e na produtividade. Porto Alegre: FEE, 2015.

BANCO MUNDIAL. Envelhecendo em um Brasil mais velho. Washington, DC: Banco Mundial, 2011. Disponível em: http://siteresources.worldbank.org/BRAZILINPOREXTN/Resources/3817166-

1302102548192/Envelhecendo_Brasil_Sumario_Executivo.pdf. Acesso em: 18 out. 2016.

BALSADI, O.V.; GRAZIANO DA SILVA, J.F. A polarização da qualidade do emprego na agricultura brasileira no período 1992-2004. Economia e Sociedade, Campinas, v.17, n.3, p.495-526, dez. 2008.

BUAINAIN, A.M. et al. Sete teses sobre o mundo rural brasileiro. Revista de Política Agrícola, Brasília, v.22, n.2, p.105-121, 2013.

CAMARANO, A.A et al. A população brasileira e seus movimentos ao longo do século XX. In: CAMARANO, A.A. (Org.). Novo regime demográfico: uma nova relação entre população e desenvolvimento. Rio de Janeiro: IPEA, 2014. p.81-116.

CAMARANO, A.A.; ABRAMOVAY, R. Êxodo rural, envelhecimento e masculinização no Brasil: panorama dos últimos 50 anos. Rio de Janeiro: IPEA, 1999. Disponível em: http://www.dominiopublico.gov.br/download/ texto/td_0621.pdf. Acesso em: 25 out. 2015.

CAMARANO, A.A.; KANSO, S. PNAD 2009: primeiras análises: tendências demográficas. Brasília: IPEA, 2010. 
CARVALHO, J; WONG. L.L.R. A transição da estrutura etária da população brasileira na primeira metade do século XXI. Cadernos de Saúde Pública, Rio de Janeiro, v.24, n.3, p.597-605, mar. 2008.

FUNDAÇÃO DE ECONOMIA E ESTATÍSTICA SIEGFRIED EMANUEL HEUSER FEE. FEE dados 2016. Porto Alegre, 2016. Disponível em: http://www.fee.rs.gov.br/. Acesso em: 10 jun. 2016.

GODOI, D.S. A transição demográfica e os impactos sobre o mercado de trabalho brasileiro. 2014. 70f. Monografia (Bacharel em Ciências Econômicas) Faculdade de Ciências Econômicas, Universidade Federal do Rio Grande do Sul, Porto Alegre. Disponível em: http://hdl.handle.net/10183/109373. Acesso em: 02 jun. 2016.

GRAZIANO DA SILVA. A nova dinâmica da agricultura brasileira. Campinas: Editora da Unicamp, 1996.

KAGEYAMA, A. et al. O novo padrão agrícola brasileiro: do complexo rural aos complexos agroindustriais. In: DELGADO, G.C. et al. (Org.). Agricultura e políticas públicas. Brasília: IPEA, 1990. p.113-223.

KIELING, R.I. Janela de oportunidade demográfica: um estudo sobre os impactos econômicos da transição demográfica no Brasil. 2009. 103f. Dissertação (Mestrado em Economia) - Programa de Pós-Graduação em Economia, Universidade Federal do Rio Grande do Sul, Porto Alegre. Disponível em: <http://hdl.handle.net/10183/18878>. Acesso em: 13 dez. 2016.

MAIA, A.G. O esvaziamento demográfico rural. In: BUAINAIN, A.M. et al. O mundo rural no Brasil século 21. Brasília: Embrapa, 2014. p.1081-1099.

SPANEVELLO, et., al. A problemática do envelhecimento no meio rural sob a ótica dos agricultores familiares sem sucessores. Desenvolvimento em Questão, ljuí, v.15, n.40, p. 348-372, jul./set. 2017.

NEVES, J.A.S.; SCHNEIDER, S. Brazilian demographic transition and the strategic role of youth. Espace Populations Sociétés, Lille, v.2, n.3, p.2-20, 2015.

SCHNEIDER, I. Êxodo, envelhecimento populacional e estratégias de sucessão na exploração agrícola. Porto Alegre: FEE, 1994.

SILVESTRO, M. et al. Os impasses sociais da sucessão hereditária na agricultura familiar. Florianópolis: EPAGRI; Brasília: NEAD, 2001.

SINGER, P. Economia política da urbanização. 11.ed. São Paulo: Brasiliense, 1987.

VEIGA, J.E. da. Cidades imaginárias: o Brasil é menos urbano do que se calcula. Campinas: Autores Associados, 2002.

WONG. L.L.R.; CARVALHO, J.A. O rápido processo de envelhecimento populacional do Brasil: sérios desafios para as políticas públicas. Revista Brasileira de Estudos Populacionais, São Paulo, v.23, n.1, p.5-26, jan./jun. 2006. 
ZUANAZZI. P.T. A taxa de fecundidade no RS por regiões funcionais e características socioeconômicas: o desafio da transição demográfica. Indicadores Econômicos, Porto Alegre, v.42, n.4, p.109-122, 2015. 